\title{
Life Style Modification for Reducing of Premenstrual Syndrome among nursing students
}

\section{Heba Mohammed Ibrahim ${ }^{1}$, Rehab Mohamed Abdelhady ${ }^{2}$ and Hemmat Mostafa Elbana ${ }^{3}$}

(1) Clinical instructor of Technical institute of nursing Touch-School of nursing (2) Assistant. Prof of Obstetrics and Woman Health Nursing, Faculty of Nursing, Benha University (3) Assistant. Prof of Obsterics and Woman Health Nursing, Faculty of Nursing, Benha University

\section{Abstract}

Background: Premenstrual syndrome is one of the most common problems in adolescent female at reproductive age. The prevalence of PMS is about $80 \%$ of adolescent female. Aim of the study: the aim of the present study was to assess effect of life style modification on management of premenstrual syndrome among nursing student. Design: Quasi experimental study design. Setting: the study was conducted at faculty of nursing at Benha University. Sampling: purposive sample was selected. The sample consist of 300 adolescent female used to fulfill the aim of the study. Tools: 1-structured interviewing questionnaire schedule 2- Premenstrual syndrome scale assessment 3-Life style assessment tool. Results: it was illustrated that there was a highly statistical significant difference between total effect of nutritional life style on premenstrual syndrome symptoms among studied students at pre and post intervention $(p<0.001)$. The results of the study revealed that There was a highly statistical significant difference between total effect of rest and sleep on premenstrual syndrome symptoms among studied students at pre and post intervention $(\mathrm{p}<0.001)$. It was illustrated that there was a highly statistical significant difference between total effect of daily activities on premenstrual syndrome symptoms among studied students at pre and post intervention $(\mathrm{p}<0.001)$, Conclusion: PMS was significantly associated with increase of body mass index, sedentary life style, exposure to passive smoking, positive family history of premenstrual syndrome symptoms, excessive coffee drinking, and frequent consumption of fast food. Recommendation: interventional program has an effective role in reducing premenstrual syndrome symptoms

Keywords: Life style modification, Premenstrual syndrome (PMS) reducing, Nursing student.

\section{Introduction}

Premenstrual syndrome (PMS) is one of the most common problems in adolescent female at reproductive age. Premenstrual syndrome is defined as the recurrent mood and a physical symptom which is usually in the lacteal phase, and it remits in the follicular phase of the menstrual cycle (Freeman et al., 2011). The prevalence of premenstrual syndrome is about $80 \%$ of adolescent female reported mid premenstrual symptoms, 20\% $80 \%$ reported moderate symptoms, and about $5 \%$ of adolescent female had severe symptoms (Brahmbhatt, et al., 2013).
The exact causes of PMS are not clearly understood but have been attributed to hormonal change neurotransmitters, prostaglandins, diet, drug, and lifestyle. (Goker et al., 2014) the most common emotional causes of PMS include depression, irritability, and tension, crying, hyper sensitivity and mood swings (Tolossa et al., 2014). Various biosocial and psychological causes have been proposed as the cause of syndromes, including abnormal serotonin function, presence of progesterone, altered endorphin modulation of gonadotropin secretion, exercise habits, smoking, use of 
alcohol and diet rich in beef (Seedhom, et al., 2013).

Additionally, it is reported that factors such as menstrual attitudes, the culture, education of individual's mother and her working condition and menstrual problems such as dysmenorrhea may also affect the daily lives of adolescent female and can deteriorate their quality of life and social skills (Direkvand et al., 2014). The severity of PMS is associated with its duration in how it impairs the daily lives of adolescent female (Choi et al., 2010).

PMS symptoms is divided into two categories of physical changes including irritability, headache, muscles aches, fatigue, weight gain, appetite disturbance, abdominal bloating and breast pain, and psychological changes including depression, social withdrawal and anxiety, crying for not reason, and impaired daily functioning. (Kristjansdottir et al., 2013).

Adolescent females with PMS frequently complain about poor sleep quality because PMS is one of the physiological disorders that may change the sleep quality by causing sleep problems such as insomnia, hyper insomnia, exhaustion, fatigue, difficulty of concentration, and nightmares. Especially adolescent female with sever PMS have greater sleep problems (Ozisik et al., 2012).

PMS is an important problem which decreases adolescent female's self confidence, impairs physical, mental and social health, causes the labor loss, negatively affects the daily life, sleep quality, social activities, family relation, attendance on lessons and academic achievements and consequently decreases the quality of life (Karout et al., 2012). Thus, the detection of adolescent females with PMS, determination of their frequent symptoms, and the definition of relevant variables increasing these symptoms may guild the intervention (Such as giving information, developing positive attitudes, and increasing the coping mechanism regard the menstrual cycle and PMS) to be planned in decreasing the PMS induced problems (Selcuket al., 2014).

\section{Significance of the study}

The prevalence of PMS is approximately $20-32 \%$ of premenopausal adolescent female and $30-40 \%$ in reproductive adolescent female and reported a $36.4 \%$ rate among nursing students. PMS prevalence rates can vary due to cultural characteristics, sample differences, and diagnostic methods. The prevalence of premenstrual symptoms was found to be 80.2\% among El- Minia university student, Egypt (EImalky and Ebrahem., 2015). In addition, it was found that, more than three quarters $(77.7 \%)$ of rural adolescent girl had experienced PMS (Yassin, 2012).

Premenstrual syndrome (PMS) is a significant health issue for adolescent female with a reported prevalence of $47.8 \%$ premenstrual syndrome can negatively affect adolescent female lives for up to six days monthly. Common symptoms of PMS include depression, mood labiality, abdominal pain, breast tenderness, headache and fatigue PMS is associated with increased sick days, impaired work productivity, impaired martial relationships and homemaking difficulties, and impaired functioning; reduced quality of life has been reported in collegiate women suffering from PMS with decreased educational productive, disruptions in social activities, and impairments in family relations (Oraby et al., 2016).

Premenstrual syndrome is among the commonest gynecological problems among adolescent female also incorrect beliefs regarding menstrual complaints do not warrant the attention of health care providers 
that lead the adolescent female suffer in salient. The study will be add to the body of nursing knowledge about associated factors that affects the severity of PMS and the effect of life style modification in premenstrual syndrome among university students to improve quality of life among this target of population, the study might also help in the development of appropriate polices, plans and intervention programs for the management and treatment of PMS (Keyhole \& Mestogullari, 2015).

\section{Aim of the study \\ The aim of this study is to assess effect of life style modification for management of premenstrual syndrome among nursing student.}

\section{Research hypothesis:}

Life style modifications will reduce of premenstrual syndrome among nursing students.

\section{Subjects and Methods \\ Research Design:}

Quasi experimental study design was utilized to fulfill the aim of this study.

\section{Study setting:}

The present study was conducted in the faculty of nursing affiliated at Benha University.

This setting was chosen because large numbers students attending for learning Also they cover a wide range of population with different socio-demographic and obstetrical characteristics. Also nurses' students are in great needs for continuous education.

\section{Sampling:}

Sample type: Purposive sample.

\section{Sample size:}

This study included three hundred (300) adolescent female with moderate premenstrual syndrome symptoms at the time of data collection.

\section{Inclusion criteria:}

Adolescent female with premenstrual syndrome symptoms, not married, without medial or gynecological disorder and not having any treatment for premenstrual syndrome symptoms and agree to participate in the study.

\section{Tools of data collection:}

The data were collected by the following tools:

\section{Tool I: A structured interviewing} questionnaire Sheet: It was designed and translated into Arabic language by the researcher after reviewing related literature under guidance of the supervisors and was validated by highly qualified professional professors in the field. The interview was utilized to collect the necessary data about the study subjects keeping in mind the educational level of each student. It consisted of two parts as.

Part (1) Socio-demographic data: Personal data of student to assess their socio-economic status included the following items (Age, Academic year, Residence, Mother education).

Age

* Academic year (assess the highest level of education of both and ways to access to health information).

* Residence: Urban or rural.

\section{* Mother's education level:}

1- Illiteracy

2- Read and write

3- Basic education

4- Secondary education

5- University education 


\section{Part (2): Menstrual history:}

It Concerned with menstrual characteristics of students as (age of menarche duration of bleeding - amount of bleeding, frequency, regularity and bleeding between menses).

Tool II: Premenstrual syndrome scale assessment (PMSS). adopted from (Sankar, 2014) to measure the student's severity of premenstrual syndrome comprised 40 question with three subscales: Physiological symptoms as ( tenderness of breast, headache ,weight gain, abdominal swelling).Psychological symptoms as(irritability, tension ,mood swings ,sleep changes).behavior symptoms as(social withdrawal ,be more sense ,fatigue ,guilty).

\section{Scoring system of premenstrual syndrome:}

Each item of the attitudes was assigned as score (3) was given for very severe and (2) used for severe score and (1) for moderately and (0) used for not found score.

The total score of premenstrual syndrome was classified into:

- $\quad$ sever: $>75 \%$

- moderate :50\%-75\%

- mild: $<50 \%$

Tool (III): Life style assessment tool.

Used to evaluate health life style of adolescent female during premenstrual period at pre and post intervention phases as (healthy nutrition, daily activities, Comfort and Sleep, Personal hygiene).

\section{Scoring system of lifestyle modification:}

Each item of the attitudes was assigned as score (3) was given for usually and (2) used for sometimes and score (1) for never.

The total score of life style was classified into:

- High satisfied: $>75 \%$

- $\quad$ Satisfied :50\%-75\%

- Unsatisfied: $<50 \%$

\section{Operational Design:}

\section{Preparatory phase}

During this phase, the researcher reviewed local and international literature to get more knowledge about the study. This also helped in designing the study tools.

\section{Validity:}

Tools were reviewed by a panel of five experts in the field of Obstetrics and gynecological nursing and psychiatric nursing to test its content validity. Modifications were done accordingly based on their judgment.

\section{Reliability:}

Reliability was done by Cronbach's Alpha Coefficient Test which revealed that each item of the utilized tools consisted relatively homogeneous items.

\section{Ethical considerations:}

- Each female student was informed about the purpose and benefits of the study at the beginning of interview and time throughout the study.

- An oral consent was obtained from each female student before starting the data collection.

- Privacy and confidentiality was ensured throughout the study process, where personal data were not disclosed, and the students before starting data collection.

- Each female student was informed that, participation is voluntary and each female student had a choice to continue or withdraw from the study

- Ethics, values, culture and beliefs were respected.

\section{Pilot study}

A pilot study was conducted on a sample of $10 \%$ about 30 students of cases. It was done to test the study tools in terms of clarity 
and feasibility, and the time required to be applied and to assess the degree of students ' understanding of the questionnaire and acceptance to be involved in the study. Following pilot study the questionnaire was reconstructed and necessary modifications were done to reach the final form pilot study was excluded from study.

\section{Field work:}

An official permission from the Dean of the Faculty of Nursing, Benha University to conduct the study. The study started from the beginning of July, 2018 to the end of January, 2019 covering six months. The researcher visited the pre mentioned setting from 9 am to $2 \mathrm{pm}$, three days per week (Sunday, Tuesday and Thursday) to collect data from female nursing students until sample size was completed.

The following phases adapted to fulfill the aim of the current study: assessment, planning, implementation and evaluation.

\section{1-Assessment phase:-}

The researcher visited Faculty of Nursing, Benha University from 9 am to 2 pm, three days per week (Sunday, Tuesday and Thursday) to collect data from female nursing students until sample size was completed.

- This phase encompassed interviewing students willing to participate in the study.

- The researcher greeted each student at the beginning of the interview, explained the aim, duration of session and activities of the study and took informed oral consent.

- The researcher used pretest (A Structured self-administrated questionnaire sheet and modified likert scale for students' premenstrual syndrom) to the students that are found faculty of nursing in the first day before conducting the program and it was handling to the researcher in the second day after the nurses fulfilled the questionnaire.

- The researcher distributed (A Structured self-administrated questionnaire sheet and modified likert scale for students' life style) to the other students in the second day.

- Also, the researcher handled (A Structured self-administrated questionnaire sheet and modified likert scale for students' life style) from the students in the third day and distributed tools to the students. Thus, until the studied student size completed.

- The average time required for completion of the questionnaire was around (20-30) minutes.

- The pretest phase took four months from the researcher until finished.

2-Planning phase:-Based on the result of analysis of the pretest for severity of premenstrual syndrome and healthy life style.

\section{3-Implementation phase (field work):-}

- Maternity nurses divided into 30 groups equally and each group contains (10) student.

- The researcher conducted theoretical sessions, each session last from 2 hours. Each group took one session and took another session when needed.

- The researcher explained to the students group in the premenstrual syndrome and at the end of the session researcher distributed instructional guidelines which were explained by pictures.

- Different teaching methods were used including discussion, enhancing active participation and brain storming. 
- Posttest was done to each group.

- These steps were done to all groups.

- This phase took two months from the researcher until finished.

\section{4- Evaluation phase}

- After implementation of educational program and administered the instructional guidelines, students' severity of premenstrual syndrome and health lifestyle were assessed by posttest.

- The posttest phase took four months from the researcher until finished.

\section{Administrative design:}

Official letters had been obtained from dean of faculty of nursing, Benha University concerned the title, objectives, tools and the study technique would be illustrated to the administrators of the previously mentioned setting to gain their cooperation which is needed to allow the investigator to meet the students.

\section{Limitation of the study:}

Something there was some difficulty in gathering students at the same time due to lectures and clinical training. Some student girls couldn't tolerate to complete all questionnaire sheets with the researcher because of the long of questions. So it was important to know the name of students, time of lectures and clinical training to facilitate gathering them.

It was difficult to follow up the chosen females and continue more especially after many cycles of menstruation in some females.

\section{Results}

Table (1) illustrates that $62.0 \%$ near than two thirds of the studied student age was ranged from 19-21 years old with mean age of 20.86 \pm 1.65 .In addition $30.0 \%$ of them attached at the second academic year. Moreover $63.0 \%$ of them lived at rural settings. Also $79.0 \%$ more than three quarters of their mothers had a secondary education and $68.0 \%$ more than two thirds of them were house wives.

Table (2) reveals that more than half( 59.0)\% of the studied student had a menarche at age from 11-13 years in addition majority ( $88.0) \%$ of them had a menstrual blood flow from 3-5 days. Moreover $83.0 \%$ of them had a regular menstruation and only $24.0 \%$ of them had a bleeding between menstrual cycles.

Table (3) reveals that mean score of physiological symptoms of premenstrual syndrome among studied students at pre and post intervention phases. It was illustrated that there was a highly statistical significant difference between total physiological symptoms of premenstrual syndrome among studied students at pre and post intervention $(\mathrm{p}<0.001 * *)$.

Figure (1) reveals that there was highly statistical significant difference between effect of body mass index and premenstrual syndrome among studied students at pre intervention phase.

Figure (2) illustrates that there was a highly statistical significant difference between total physiological, psychological, behavioral symptoms of premenstrual syndrome among studied students at pre and post intervention $\left(\mathrm{p}<0.001^{* *}\right)$.In addition the total behavioral symptoms mean score decrease from $9.0733+5.43552$ to $1.8200+1.91802$ at post intervention

Figure (3) illustrates that there was positive effect after intervention 
Table (1): Distribution of personal characteristics of studied sample $(\mathrm{N}=300)$

\begin{tabular}{|l|c|c|}
\hline \multicolumn{1}{|c|}{ Personal characteristics } & No & \% \\
\hline Age In years & & 62.0 \\
\hline $19-<21$ & 186 & $38 ; 0$ \\
\hline $21-23$ & 114 & $\mathbf{2 0 . 8 6 \pm 1 . 6 5}$ \\
\hline Mean $\mathbf{2 S D}$ & \multicolumn{2}{|c|}{} \\
\hline Academic year & 71 & 23.7 \\
\hline First & 90 & 30.0 \\
\hline Second & 73 & 24.3 \\
\hline Third & 66 & 22.0 \\
\hline Fourth & & 37.0 \\
\hline Residence & 111 & 63.0 \\
\hline Urban & 189 & 1.0 \\
\hline Rural & & 5.3 \\
\hline Mother educational level & 3 & 79.0 \\
\hline Illiterate & 16 & 14.7 \\
\hline Read and write & 237 & 68.0 \\
\hline Secondary & 44 & 32.0 \\
\hline University & 204 & \\
\hline Occupation of mother & 96 & \\
\hline House wife & & \\
\hline Working & & \\
\hline
\end{tabular}

Table (2): distribution of menstrual history of studied sample $(\mathrm{N}=300)$

\begin{tabular}{|l|c|c|}
\hline \multicolumn{1}{|c|}{ Variable } & No & $\%$ \\
\hline Age of menarche (in years) & & \\
\hline $11-13$ & 177 & 59.0 \\
\hline$>13$ & 123 & 41.0 \\
\hline Mean $\mathbf{n}$ SD & $\mathbf{1 1 . 8 6} \pm \mathbf{1 . 9 4}$ \\
\hline Days of the menstrual cycle & & \\
\hline Less than 3 days & 30 & 10.0 \\
\hline 3-5 days & 264 & 88.0 \\
\hline Moe than 5 days & 6 & 2.0 \\
\hline Regular menstruation & & \\
\hline Yes & 249 & 83.0 \\
\hline No & 51 & 17.0 \\
\hline Bleeding between menstrual cycles & & \\
\hline Yes & 72 & 24.0 \\
\hline No & 228 & 76.0 \\
\hline
\end{tabular}




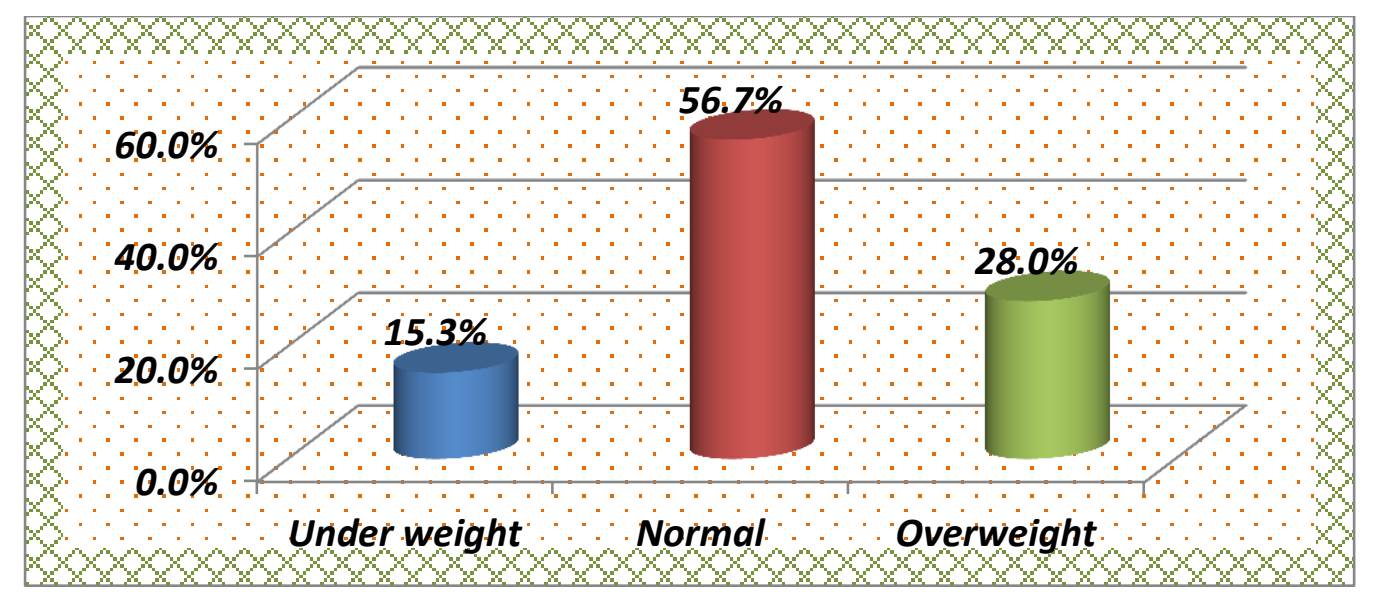

Figure (1): percentage distribution of body mass index of the studied students.

Table (3): Mean score of physiological symptoms of premenstrual syndrome among studied sample at pre and post intervention phases.

\begin{tabular}{|c|c|c|c|c|}
\hline \multirow[t]{2}{*}{ Physiological symptoms } & $\begin{array}{c}\text { Pre- } \\
\text { intervention }\end{array}$ & $\begin{array}{c}\text { Post- } \\
\text { intervention }\end{array}$ & \multirow{2}{*}{$\begin{array}{l}\text { Paired t } \\
\text { test }\end{array}$} & \multirow[t]{2}{*}{$P$ value } \\
\hline & Mean \pm SD & Mean \pm SD & & \\
\hline 1-Tenderness ,pain of breast & $.9467 \pm .66339$ & $.1400 \pm .36692$ & 18.744 & $<0.001 * *$ \\
\hline 2- Abdominal swelling & $.9733 \pm .69463$ & $.2400 \pm .48715$ & 15.302 & $<0.001 * *$ \\
\hline 3- Weight gain & $.9000 \pm .74860$ & $.1600 \pm .36783$ & 14.420 & $<0.001 * *$ \\
\hline 4- Headache & $.8667 \pm .80824$ & $.1400 \pm .34815$ & 13.601 & $<0.001 * *$ \\
\hline 5- Dizziness ,fainting & $.9267 \pm .81180$ & $.1933 \pm .41283$ & 13.999 & $<0.001 * *$ \\
\hline 6- Tiredness & $1.3200 \pm .77130$ & $.3467 \pm .47750$ & 25.766 & $<0.001 * *$ \\
\hline 7- palpitation & $1.0733 \pm .76935$ & $.3067 \pm .46265$ & 17.118 & $<0.001 * *$ \\
\hline $\begin{array}{l}8 \text { - pain and discomfort in the } \\
\text { pelvis }\end{array}$ & $1.5333 \pm .84874$ & $.4667 \pm .50056$ & 23.684 & $<0.001 * *$ \\
\hline 9- abdominal cramps & $1.5400 \pm .82438$ & $.4333 \pm .49720$ & 26.736 & $<0.001 * *$ \\
\hline 10. Changing bowel habits & $1.0600 \pm .76175$ & $.2333 \pm .42437$ & 12.346 & $<0.001 * *$ \\
\hline 11- Increase appetite & $.8333 \pm .81444$ & $.2067 \pm .40627$ & 13.652 & $<0.001 * *$ \\
\hline 12- Pain and general aches & $1.3000 \pm .82535$ & $.1067 \pm .30972$ & 19.536 & $<0.001 * *$ \\
\hline Food cravings (sugar, salt( 13- & $.9067 \pm .82207$ & $.2800 \pm .45050$ & 12.187 & $<0.001 * *$ \\
\hline $\begin{array}{l}\text { 14- changes in the skin, rashes } \\
\text { and pimples }\end{array}$ & $.7667 \pm .81444$ & $.2133 \pm .41103$ & 11.575 & $<0.001 * *$ \\
\hline 15- nausea, vomiting & $.8533 \pm .70840$ & $.2133 \pm .41103$ & 14.666 & $<0.001 * *$ \\
\hline 16- pain muscles and joints & $1.2067 \pm .72627$ & $.3800 \pm .56366$ & 22.022 & $<0.001 * *$ \\
\hline
\end{tabular}




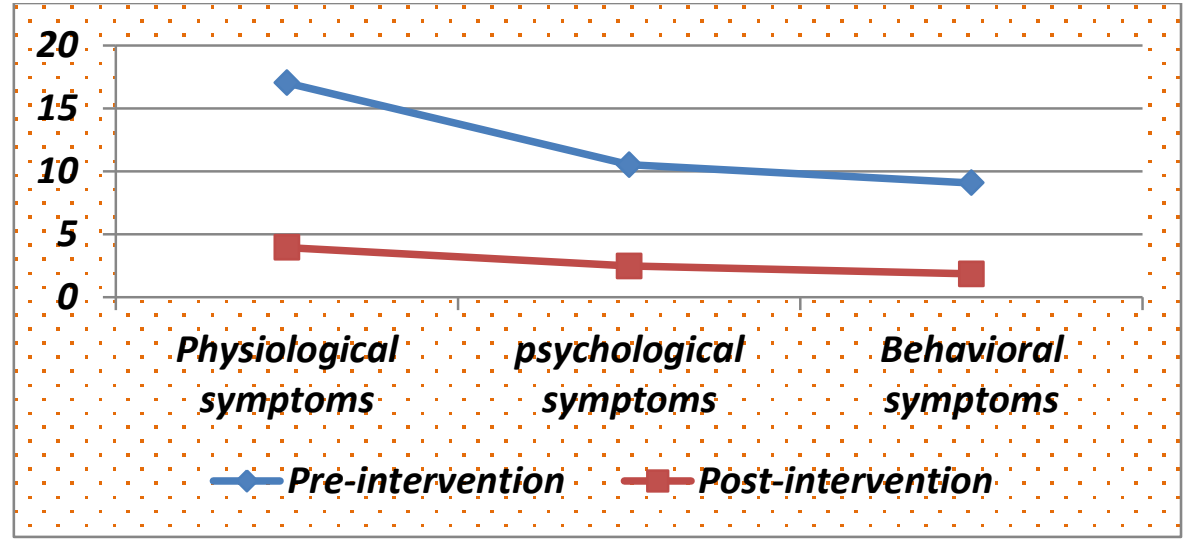

Figure (2): Mean score of premenstrual syndrome symptoms of the studied sample pre and post intervention.

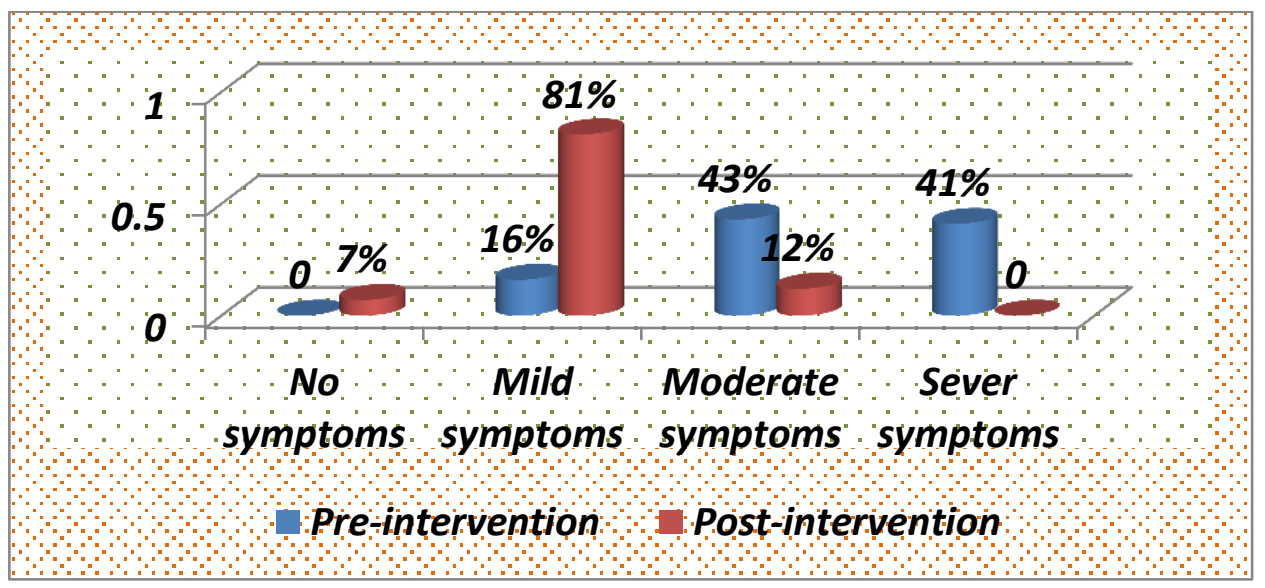

Figure (3): Total level of premenstrual syndrome symptoms among studied students at pre and post intervention phases.

\section{Discussion}

Life style plays an important role in biopsychological health. There is an interlock relationship between health problems and life style. In other words, life style is one of the most important influential factors on individual's health and illness (Tashiro, 2018). A healthy lifestyle is the first step to managing PMS. For many women, lifestyle approaches are often enough to control symptoms (Lentz, 2018).

Regarding personal characteristics of the studied students, the present study illustrated that near than two thirds of the studied student age was ranged from 19-21 years old with mean age of $20.86 \pm 1$.65.In addition near than one third of them attached at the second academic year. Moreover less than two thirds of them lived at rural settings. Also more than three quarters of their mothers had a secondary education and more than two thirds of them were house wives.

This finding was supported with ( Refaat \&Gabeer 2017) they conducted study to improve life style among nursing students regarding menstrual disorders through an educational training program at the faculty of nursing, Benha university and found that more half of students were aged from 2025years, with a mean of age SD 21.57 2.6 years. More than three quarters of them live at rural area. Also, in the same line Victor et al.,

\section{JNSBU}


(2019) they conducted study to assess quality of life among university students with premenstrual syndrome, in Brazil and found that most students were between 18 and 24 years old

Conversely, this result was in disagreement with Tsegaye \&Getachew (2017) they conducted a study on premenstrual dysphonic disorder and associated factors among female health science students in Wollo University, Ethiopia, 2017/18, and found majority of the students were in the age group between 15 and 25 years. And the rest were aged above 26 years and one third of studied student were at first academic year

Also, this finding was in agreement with Keely, et al. (2017), and reported that there were significant correlations among education, cognitive variables and health behaviors, including attitudes and intended choices that can be related to physical activities as well as the intake of healthy diet leading to improving general health in women. Also, Abdel-Wahab et al., (2017) they reported that there was a highly statistical significant difference among behavioral changes symptoms related symptoms at different phases of intervention. Increasingly, there was more decrease in mean score regarding behavioral change related symptoms at Follow up phase than Post-test phase

\section{Conclusion}

\section{Based on the results of the present study and research questions the study concluded that:-}

There was a highly statistical significant difference between total physiological symptoms of premenstrual syndrome among studied students at pre and post intervention.
There was a highly statistical significant difference between total behavioral symptoms of premenstrual syndrome among studied students at pre and post intervention. There was a highly statistical significant difference between total life style among studied students at pre and post intervention. There was a highly statistical significant difference between total effect of daily activities on premenstrual syndrome symptoms among studied students at pre and post intervention $(p<0.001)$, There was a highly statistical significant difference between total effect of rest and sleep on premenstrual syndrome symptoms among studied students at pre and post intervention $(\mathrm{p}<0.001)$

There was positive correlation between effect of age, academic year, body mass index and premenstrual syndrome \&life style among studied students at pre intervention phase. There was positive correlation between premenstrual syndrome and life style among studied students at pre intervention phase. Finally life style modification was better route in management of premenstrual syndrome among nursing students.

\section{Recommendation}

In the light of findings of current study, the following recommendations were suggested:

1- Introduction of a reproductive health component into school and college health education program could help in providing correct and current information, education, and support to students regarding reproduction in general and menstrual problems in particular.

2- Encouraging the female adolescents to adopt a healthy life style would be essential for those have troublesome menses with PMS. 


\section{Further study:}

1- This research should be containing large sample of populations and wider geographic scope to emphasize our conclusion.

2- Using a longitudinal study design are recommended.

\section{Reference}

Abdel-Wahab O., Mohammed N., Ahmad A. and Ouda S. (2017). Syndrome Relieving Premenstrual feet Reflexology on -Effect of Self. Menoufia Nursing Journals - November2017 / 2(2). Pp $1: 19$.

Brahmbhatts., S., Sattig eir, BM., Shah, H., Kumar,A. and Choi, D., Lee, DY., Lehert, P.,Lee, IS., Kim, SH., and Dennerstein, L., (2010). the impact of premenstrual symptoms concavities of daily life in Korean women, J, Psychosom obstet Gynaecol 31 :10-5.

Direkvand, A., Sayahmiri, K., Delpisheh, A., and Sattar, K., (2014). Epidemiology of Premenstrual syndromes - systematic review and meta - analysis study, J Clinic Deign Res; 8: 106-9.

Elmalk, E., and Ebrahem, M. (2015). Effectiveness of psycho- Educational Nursing Intervention on aldolessecents premenstrual syndrome and selfEfficacy master thesis of department of psychiatric mental health nursing, faculty of nursing, Menoufia University, P.002.

Freeman, EW., Sammel, MD., Lin, H., Rickels, K., and Sondheim SJ.(2011). Clinical subtypes of premenstrual syndrome and Response to seatrain treatment, Obstetrics and Gynecology: 118 (6) : 1293-1300.

Goker, A., Artunc - Ulkumen, B., Aktenk, F., and Ikiz, N. (2014). Premenstrual Syndrome in Turkish medial students and their quality of life, $\mathbf{J}$ Obstet Gynaeeol.;20 :14.

Kahyaglu, H., and Mestogullari, E.(2015). Effect of premenstrual syndrome on work related quilty of life in Turkish Nurses, Masterthesis, Dpartment of Obsterics and Gynecology. Nurisng Faculty of Health Scienes, Balkan Campus, 22030 Edirn, Turkey, P. 78.

Karout, N., Hawais, M., and Aluwaijri, S. (2012). Prevelence and Pattern of menstrual disorders among Lebanese nursing students. East Mediterr Health ; 18 (4) : 346-52.

Kelly, S. A., Melnyk, B. M., Jacobson, , J. A. (2017). Correlates Among Healthy Lifestyle Cognitive Beliefs, Healthy Lifestyle Choices, Social Support, and Healthy Behaviors in Adolescents: Implications for Behavioral Change Strategies and Future Research.Journal of Pediatrics Health Care, 25(4), 216-23.

Krisjansdottir,Jolsson, GI.,Sundelin, and Neasden, T. (2013). :Self - reported health in adolescent girls varies according to the seasonand itsrelation to medication and hormonal contraception descriptive Study. Eur J ontracept' Rpord Health are;18 :343-54.

Lentz G. , (2018).“1ry, 2nd dysmenorrhea, PMS and premenstrual dysphoric disorder: etiology, diagnosis, management," in Comprehensive Gynecology, G. M. Lentz, R. A. Lobo, D. M. Gershenson, and V. L. Katz, Eds., 
chapter 36, Mosby, Elsevier, Philadelphia, Pa, USA, $9^{\text {th }}$ edition,.

Oraby, F., Fawaz, M., and El- Sharkawy, N. (2016). Reproductive demography predictors of premenstrual syndrome severity among University student, IOSR Journal of Nursing and Health science, 5ver, p.10.

Ozisik, Karman, HI., Tanriverd, I G. and Degrimenci, Y. (2012). Subjetive sleep quality in premenstrual syndrome. Gyneol Endocrinology :28 (8:661-4. dol:10.3 109/09513590. 20111. 650769.

perceptions, practices, and issues. Health Care for Women International; 23(1):59-70.

Refaat A. and Gabeer M., (2017). improve life style among nursing students regarding menstrual disorders through an educational training program at the Faculty of Nursing, Benha University. International Journal of Nursing Science 2017, 7(2): 35-43 DOI: 10.5923/j.nursing.20170702.01.

Sanker S., (2014). Validity and Reliability study of Premenstrual Syndrome Sale (PMSS).Master theis Annandale University, P.5.

Seedohm, A., Mohammed, E., and Mahfouz, E. (2013). Life style factors associated with premenstrual syndrome among El- minia University students, Egypt. Hindawi Puplisheing orporation ISRN Publi health; ID 617123P.6.

Tashiro J. (2018). Exploring health promoting lifestyle behaviors of Japanese college women :

\section{Tolossa, F.,Wakjira and Bekele M., Legess.} (2014). Prevalence, impats and medical management of premenstrual syndrome among famele student; Cross - sectional study in college of health sciences, mekella university, ekella, Northern Ethiopia BMC Women's Health, 14 : 52.

Tsegaye D and Getachew W (2017). Premenstrual dysphoric disorder and associated factors among female health science students in Wollo University, Ethiopia, 2017/18, Tsegaye and Getachew Maternal Health, Neonatology, and Perinatology (2019) 5:8. https://doi.org/10.1186/s40748-0190102-z.

Yassin, SH. (2012). Herbal remdedy used by rural adolescent girls with menstrual disorders. Journal of American science; 8 (1): 467-473. 
تعديل نمط الحياه لتقليل متلازمه ما قبل الحيض بين طالبات التمريض

هبه محمد ابراهيم - رحاب محمدعبدالهادي - همت مصطفى البنا

متلازمة ما قبل الحيض هى واحدة من المشاكل الأكثر شيو عا بين الفتيات المر اهقات فى سن الإنجاب .

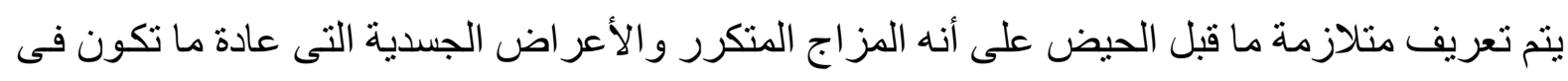

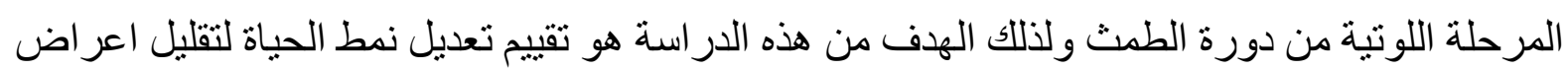

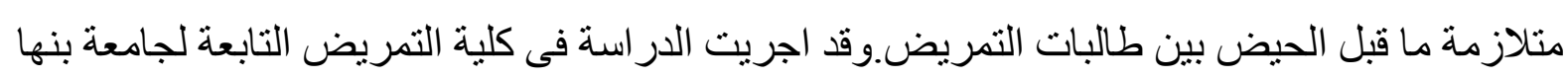

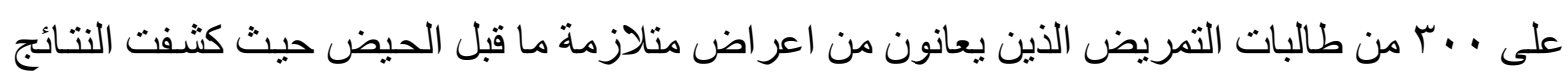

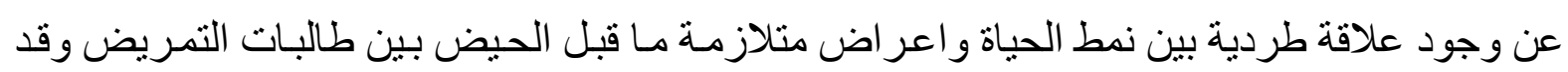

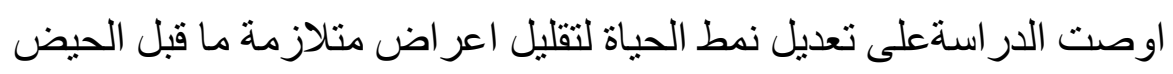

